\title{
DESENVOLVIMENTO SUSTENTÁVEL: UM DISCURSO SOBRE A RELAÇÃO ENTRE DESENVOLVIMENTO E NATUREZA ${ }^{1}$
}

\author{
Hugo Juliano Duarte Matias² \\ José de Queiroz Pinheiro \\ Universidade Federal do Rio Grande do Norte, Natal, Brasil
}

\begin{abstract}
Resumo: Trata-se do estudo de definições de desenvolvimento sustentável, elemento fundamental de repertórios interpretativos para a relação entre desenvolvimento e natureza. As definições respondiam a um questionário aplicado a 355 estudantes de vários cursos de uma universidade federal. Realizou-se uma análise de conteúdo que buscou a concepção de natureza e sua relação com desenvolvimento nessas definições. Foram encontradas três matrizes discursivas: (a) "economicista") - a necessidade de desenvolvimento subordina a necessidade de preservação da natureza, cujo sentido é "recursos naturais"; (b) discurso "bem intencionado" - a necessidade de desenvolvimento subordina a de preservação da natureza, cujo sentido é "fragilidade"; (c) "esvaziado" - desenvolvimento e natureza são disjuntos. Conclui-se sobre a importância do estudo da atribuição de significado à natureza para explicar como as pessoas pensam a relação entre desenvolvimento e natureza, e sobre como essas matrizes discursivas podem justificar práticas sociais.
\end{abstract}

PALAVRAS-CHAVE: Desenvolvimento sustentável; comportamento pró-ambiental; concepção de natureza; Psicologia Ambiental.

\section{SUSTAINABLE DEVELOPMENT: A DISCOURSE ABOUT THE RELATION BETWEEN DEVELOPMENT AND NATURE}

\begin{abstract}
This study presents the analysis of definitions of sustainable development, as a basic element of interpretative repertoires for the relation between development and nature. Three hundred and fifty five students of several courses of a federal university answered a questionnaire, providing the definitions, thereafter submitted to content analysis to examine the concept of nature and its relation with development. Three discursive matrixes were found: (a) the "economic bias" one - the necessity of development subordinates the need of nature preservation - nature is a "natural resources"; (b) the "good intentions" discourse - the necessity of development subordinates the necessity of preservation - nature is "fragility"; (c) the "empty" one - development and nature are separate. It is concluded that the attribution of meaning to nature is important to explain how people think about the relation between development and nature, and that these discursive matrixes may justify social practices.
\end{abstract}

KEYWORDS: Sustainable development; pro-environmental behavior; concept of nature; Environmental Psychology.

O tema do desenvolvimento sustentável tem feito convergir interesses políticos, científicos e da sociedade de modo geral, já que, num contexto de agravamento da crise ambiental e do aumento de consciência dessa crise, o desenvolvimento sustentável foi e continua sendo apresentado como uma proposta e tentativa de solucionar tal problema.

Esse tema tem despertado o interesse de cientistas sociais, ecólogos, planejadores urbanos, economistas e políticos. Também de psicólogos de diversos países, o que se evidencia pelo surgimento de pesquisas e expressiva bibliografia acerca de temas relacionados ao desenvolvimento sustentável (Bonnes \& Bonaiuto, 2002; McKenzie-Mohr \& Oskamp, 1995; Oskamp, 2000; Pol, 2002; Schmuck \& Schultz, 2002).

Segundo Pol (2001), no que diz respeito à crise ambiental, esse conceito tem a vantagem de se apresentar como ponto de encontro entre interesses econômicos de desenvolvimento, que não podem ser ignorados, e interesses ecológicos de preservação das condições 
ambientais de vida. Principalmente, traz consigo a virtude de promover o reconhecimento de fatores comportamentais, sociais, etc., como incorporados à questão ambiental, o que coloca a Psicologia como saber estratégico no enfrentamento dos problemas ambientais, melhor dizendo, problemas humano-ambientais, e o próprio homem como objeto de pesquisas no que diz respeito aos problemas ambientais e à sua solução (Pinheiro, 2003; Schmuck \& Vlek, 2003).

Segundo o Informe Brundtland (Comissão Mundial sobre Meio Ambiente e Desenvolvimento, 1988), o desenvolvimento sustentável é aquele que garante "atender as necessidades do presente sem comprometer a capacidade de as gerações futuras atenderem também às suas” (p. 9). Essa definição comporta alguns elementos importantes como o fato de que, para gerar sustentabilidade, é necessário combater a pobreza com o desenvolvimento econômico, um compromisso intergeracional, e a idéia de que o planeta dispõe de uma quantidade limitada de recursos e de uma capacidade limitada de dar condições à vida como a conhecemos. Embora isso possa ser considerado como o mainstream do desenvolvimento sustentável (Frey, 2001), há diversas tendências. O conceito é impreciso e comporta várias interpretações, muitas vezes carregadas de utopismo (Drummond, 1999), e as várias teorias que o circunscrevem se correlacionam a ideologias políticas diferentes (Frey, 2001). É um conceito com muitos defensores e críticos; certamente, um tema sobre o qual não há acordo.

Tal situação de desacordo conceitual e ideológico sobre o que é, ou deveria ser, o desenvolvimento sustentável se impõe sobre o discurso político-social acerca da relação entre desenvolvimento e natureza, gerando várias concepções sobre essa relação, tanto naqueles que dirigem a sua fala à sociedade como na própria sociedade (Aragonés, Raposo, \& Izurieta, 2000).

O conhecimento é, em geral, considerado como condição para o comportamento, muito embora essa influência varie de acordo com o tipo de conhecimento, sua utilização e a situação em questão. Nesse sentido, e a despeito da polêmica que reveste a relação entre conhecimento e conscientização ambientais e ações de conservação ecológica (Frick, Kaiser, \& Wilson, 2004; Kollmuss \& Agyeman, 2002; Scott, 2002), o comportamento próambiental depende, ao menos em parte, da maneira com que a pessoa adquire e organiza informação sobre o ambiente e de como a converte em ações no ambiente (Corral, 2001). É nesse sentido que a literatura aponta para o fato de que diversas concepções de desenvolvimento sustentável podem ser correlacionadas a outras variáveis comportamentais e ideológicas, de forma que se tornam mais compreensíveis os comportamentos e modos de pensar das populações estudadas no que concerne ao meio ambiente.
Sob a suposição de que diferentes concepções de desenvolvimento sustentável estariam relacionadas a outras variáveis, Aragonés et al. (2000) e Aragonés, Izurieta e Raposo (2003) realizaram uma análise lexicográfica de definições de desenvolvimento sustentável dadas por estudantes universitários e compararam os resultados dessa análise aos resultados de uma auto-avaliação, feita pelos estudantes, sobre seu posicionamento político. Chegaram à conclusão de que três discursos distintos acerca de desenvolvimento sustentável se correlacionaram a três posicionamentos políticos distintos.

Nunes (1999) havia realizado uma pesquisa em que analisou a ocorrência, nas definições dadas por estudantes universitários para desenvolvimento sustentável, de temas que compõem uma definição amplamente aceita. Ao comparar esses resultados com os escores obtidos pelos estudantes na escala de Ecocentrismo e Antropocentrismo (Thompson \& Barton, 1994), constatou que foi significativa a associação entre baixos escores de ambientalismo antropocêntrico e a ocorrência do tema "preocupação com gerações futuras" na definição de desenvolvimento sustentável. Esse resultado apontou para a necessidade de se considerar a relação entre o modo como as pessoas vivenciam o tempo e o seu comportamento pró-ambiental.

Embora tenha sido possível encontrar várias concepções acerca do que é desenvolvimento sustentável e sobre a relação entre desenvolvimento e natureza, as definições estudadas, tanto na Espanha quanto no Brasil, se mostraram muito pobres em conteúdo. Com relação ao Brasil, isso atesta também pesquisa realizada por Crespo (2001), em que estudou o conhecimento dos brasileiros sobre meio ambiente. Ela constatou, entre outras coisas, que, para boa parte dos brasileiros, desenvolvimento econômico e meio ambiente são duas coisas que não se afetam necessariamente, ou seja, que é perfeitamente possível o desenvolvimento econômico que não cause nenhum dano à natureza.

O estudo que passamos a relatar é um recorte de um outro mais amplo, um estudo exploratório que teve como objetivo a construção, a partir de bases empíricas, do conceito de conduta sustentável (Pinheiro, 2005). Nele, se investigou a definição de desenvolvimento sustentável fornecida por estudantes universitários, em conjunto com indicadores de comportamento pró-ambiental, perspectiva temporal e informações sócio-demográficas.

Seguindo estratégia de análise empregada em estudo anterior de nosso grupo de pesquisa (Pinheiro, Maux, \& Nunes, 2000), inspecionamos o conteúdo das definições de desenvolvimento sustentável (Pinheiro et al., 2005) para analisar a inclusão pelos respondentes das cinco categorias que, segundo a literatura da área (Barbieri, 1997; Comissão Mundial sobre Meio Ambiente e Desenvolvimento, 1988), integram o conceito: sustentabilidade 
ecológica (ECOL, ou conservação da natureza), preocupação com gerações futuras (GFUT), garantia de qualidade de vida $(\mathrm{QV})$, cooperação entre todos os países (COOP), e garantia de participação global (PART).

Como se pode observar na Tabela 1, dentre as 253 definições válidas (102 não continham nem mesmo uma categoria), nenhuma incluiu quatro ou cinco categorias, apenas três chegaram a conter três das cinco categorias consideradas, somente 35 incluíram duas categorias, enquanto 215 definições continham apenas uma categoria.

Tabela 1

Quantidades de Categorias das

Definições de Desenvolvimento Sustentável

\begin{tabular}{lrrrrrr}
\hline $\begin{array}{c}\text { Presentes na } \\
\text { definição }\end{array}$ & $\mathrm{n}$ & \% acumul. & ECOL & GFUT & QV & PART \\
\hline 0 categoria & 102 & 29 & - & - & - & - \\
1 categoria & 215 & 90 & 191 & 3 & 2 & 1 \\
2 categorias & 35 & 100 & 35 & 26 & 7 & 1 \\
3 categorias & 3 & 100 & 3 & 3 & 3 & 0 \\
\hline Total & 355 & 100 & 229 & 32 & 12 & 2 \\
\hline
\end{tabular}

Nota. A categoria COOP (Cooperação entre todos os países) não foi mencionada nas definições de DS dos respondentes. ECOL = sustentabilidade ecológica; GFUT = preocupação com gerações futuras; $\mathrm{QV}=$ garantia de qualidade de vida; PART = garantia de participação global.

A concepção de desenvolvimento sustentável (DS) apresentada pelos participantes, portanto, foi bastante limitada no que diz respeito à amplitude de dimensões do conceito, já que $90 \%$ dos respondentes incluíram no máximo uma das categorias investigadas. Adicionalmente, essa concepção de DS se mostrou bastante presa à dimensão de sustentabilidade ecológica ou conservação ambiental, uma vez que 191 definições incluíram essa categoria isoladamente ( $75 \%$ das 253 válidas, e $89 \%$ das 215 que mencionaram uma única categoria). Preocupação com gerações futuras (GFUT) é a segunda colocada em número de menções (32), bem abaixo da primeira, e tipicamente incluída em definições que já continham sustentabilidade ecológica (26/32). Considerando-se que a palavra "sustentável" tem clara relação com a dimensão temporal, mais particularmente com o futuro, continua a causar-nos estranheza que tão poucos respondentes tivessem registrado a categoria de preocupação com as gerações futuras em suas definições, o que já ocorreu em nosso trabalho anterior (Pinheiro, Maux, \& Nunes, 2000). As garantias de qualidade de vida (QV) e de participação global (PART) tiveram presença insignificante nas respostas analisadas, também repetindo resultados já observados anteriormente.
Assim, interessava-nos compreender melhor o conteúdo das definições de DS deixadas pelos estudantes universitários pesquisados. No restante deste relato, portanto, tratamos das concepções, presentes nas respostas dos estudantes universitários, de desenvolvimento sustentável e a concepção de natureza, também a relação entre elas, como possíveis indicadores do posicionamento dos participantes sobre a relação entre desenvolvimento e natureza, e de outras variáveis associadas a esse posicionamento. A suposição é que a concepção de natureza à qual uma pessoa adere condiciona o seu vínculo a um ou outro discurso sobre a relação entre desenvolvimento e natureza/meio ambiente.

\section{Método}

\section{Participantes}

Tomaram parte nesta investigação 355 estudantes de vários cursos universitários, sendo 229 mulheres $(64,5 \%)$ e 126 homens $(35,5 \%)$, com média de idade de 22,7 anos $(D P=5,05) .87 \%$ dos participantes eram solteiros, vivendo com a família de origem (73\%) ou separados dela $(14 \%)$. Embora a maioria $(88 \%)$ estudasse atualmente em universidade pública, $72 \%$ tinham estudado em escolas particulares durante os anos de ensino fundamental e médio.

\section{Procedimentos de coleta e análise de dados}

Uma carta explicativa sobre o projeto era entregue para coordenadores de cursos e/ou professores para obter autorização à coleta de dados. Uma vez assegurada tal permissão, os membros de nossa equipe compareciam à sala de aula no horário marcado com o/a professora/a, e apresentavam objetivos e instruções gerais, esclarecendo que responder ao questionário era ato voluntário, nãorelacionado ao acompanhamento ou avaliação do desempenho acadêmico no curso ou disciplina e que a concordância deles em participar seria considerada como consentimento livre e esclarecido. As eventuais dúvidas eram esclarecidas e dava-se início ao preenchimento individual dos questionários, recolhidos ao final da aplicação.

As respostas às questões abertas foram transcritas para um arquivo de texto, visando facilitar a análise de seu conteúdo. Os dados sócio-demográficos, as respostas às escalas tipo "likert" e as categorizações das respostas às questões abertas foram lançados em planilha eletrônica de dados e analisados por meio do programa estatístico SPSS for Windows.

O corpus de análise se constituiu de 218 respostas válidas, cuja média de palavras foi de $25(D P=12)$. O referencial de codificação foi elaborado a partir das hipóteses levantadas acerca do discurso social sobre desenvolvi- 
mento sustentável pelas pesquisas disponíveis. Como os estudos já referidos de Aragonés et al. (2000; 2003) sugeriram, as principais dimensões do discurso sobre desenvolvimento sustentável foram desenvolvimento e nature$\mathrm{za} /$ meio ambiente, às quais a categorização deu ênfase. Depois de uma leitura exploratória do corpus de análise, chegou-se a uma estrutura prototípica de análise das definições: DS é [D] / DS '! [N].[D”!N], isto é, desenvolvimento sustentável (DS) é um desenvolvimento específico tal que implica uma (concepção de) natureza específica e uma relação específica entre desenvolvimento e natureza.

Foram analisados os tipos de relação entre as dimensões que compunham a definição (desenvolvimento e natureza, ou "D" e "N") e a importância de cada uma na resposta - uma proposta semelhante ao modelo de análise do item sobre desenvolvimento sustentável no levantamento feito por Crespo (2001) -, e também a forma como era expressa a dimensão natureza. Essa matriz de análise gerou três formas de categorização para a dimensão natureza (ver Figura 1) e também quatro possibilidades de relação entre desenvolvimento e natureza (ver Figura 2), dando origem ao referencial de codificação que consta da Tabela 2 .

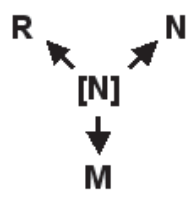

Figura 1. Formas de categorização para natureza.

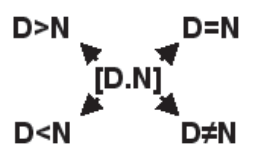

Figura 2. Possibilidades de relação entre desenvolvimento e natureza.

Tabela 2 Descrição dos temas da definição de desenvolvimento sustentáv

$D>N$ ocorre quando, na definição do respondente, a dimensão natureza é objeto de uma concessão relativa aos objetivos do desenvolvimento sócio-econômico. Expressa, portanto, maior importância para a dimensão desenvolvimento

$D<N$ ocorre quando, na definição, a dimensão desenvolvimento é possível por causa de uma concessão relativa à necessidade de proteção e sustentabilidade da natureza. Expressa, portanto, maior importância para a dimensão natureza/meio ambiente.
$D=N$ ocorre quando, na definição, a dimensão desenvolvimento tem sua importância modulada pela importância da segunda dimensão, isto é, o desenvolvimento é regulado pelo respeito à natureza, ou pela necessidade de sua manutenção. Expressa, portanto, o equilíbrio entre os interesses de desenvolvimento e a necessidade de preservação de condições ambientais desejáveis.

$D$ “' $N$ ocorre em respostas em que, embora sejam reconhecidas as duas principais dimensões que compõem a definição de DS, não é sugerida uma articulação dinâmica entre elas, ou seja, expressa a não-relação, a mútua não-afetação entre as duas dimensões, como se uma não interferisse na outra.

$R$ ocorre em expressões como "recursos naturais", ou quando a natureza é tratada como um bem, disponível ao homem, e para o seu usufruto. Subtrai à natureza seu valor intrínseco e suas características de sistema, e ao meio ambiente a sua amplitude sobre o espaço urbano.

$M$ ocorre em expressões como ambiente, meio ambiente ou natureza, sem que ao longo do texto se lhes agregue qualquer significado complementar, de forma que essa dimensão carece de sentido, ou é remetida ao sentido superficial que ocorre em usos vulgares.

$N$ ocorre com as mesmas expressões que em $\mathrm{M}$, e ainda ecossistema, no entanto, são-lhe agregados outros significados que atribuem a essa dimensão aspectos sistêmicos e/ou dinâmicos, e/ou um valor intrínseco.

Esse referencial de codificação foi testado por três juízes, que submeteram o material à categorização, gerando um índice de acordo de $84 \%$ que, sendo superior a $75 \%$, pode ser considerado adequado (Bauer, 2002).

A forma como se construiu este referencial analítico foi orientada pela Análise de Conteúdo (Bardin, 1979; Bauer, 2002; Minayo, 1992; Souza Filho, 1995). Buscava-se nas respostas a fala que atualizava um sentido já presente no discurso social sobre a relação entre as dimensões D e N, articulada a uma matriz discursiva. Com o objetivo de restituir aos dados as suas características discursivas, as matrizes discursivas foram reconstruídas a partir de uma releitura desses dados, recompondo os 
sentidos dispersos pelos conjuntos de respostas, então reunidas segundo suas semelhanças semânticas e recorrências temáticas, depois do processo de categorização das respostas e seu cômputo.

\section{Resultados e discussão}

$\mathrm{O}$ primeiro conjunto de resultados se refere às formas como a dimensão natureza/meio ambiente foi expressa nas definições dos participantes, as palavras utilizadas para isso, quaisquer expressões ou sentenças cujo objetivo tenha sido esclarecer o sentido que se pretendia dar a essa dimensão; material esse agrupado segundo afinidades de sentido em três quadros temáticos de referência diferentes, conforme visto anteriormente (Tabela 2).

Como se pode ver na Tabela 3 , a maioria dos participantes expressou a dimensão natureza/meio ambiente com idéias pouco definidas e de difícil discernimento agregadas dentro da categoria $\mathrm{M}$, que é definida como uma idéia inespecífica de natureza/meio ambiente. Ora, se o sentido dado à relação entre as duas dimensões da definição de desenvolvimento sustentável depende do significado atribuído a cada uma dessas dimensões separadamente, um significado indefinido para a natureza/meio ambiente torna a relação representacional entre essa dimensão e desenvolvimento inevitavelmente empobrecida.

Tabela 3 Distribuição da freqüência das categorias de natureza/meio ambiente

\begin{tabular}{lcc}
\hline Categorias & Freqüencia & $\%$ \\
\hline Nenhuma & 114 & 32 \\
$\mathrm{M}$ & 134 & 38 \\
$\mathrm{R}$ & 88 & 25 \\
$\mathrm{~N}$ & 19 & 5 \\
\hline Total & & \\
\hline
\end{tabular}

Em segundo lugar, vem o conjunto de idéias que se referem à natureza/meio ambiente como reserva de recursos naturais (categoria $\mathrm{R}$, definida pela idéia de que natureza/meio ambiente é o conjunto de bens naturais disponíveis ao homem). Essas idéias, em comparação ao conjunto de idéias apresentado como meio ambiente $(\mathrm{M})$, são mais específicas para conferir significado à dimensão natureza/meio ambiente, por fazer referência às suas características, lançando mão de um campo lexical mais amplo - isto é, mais palavras e idéias diferentes para dar significado a essa dimensão - e ao mesmo tempo, mais coeso para significar a idéia de recursos naturais.

$\mathrm{O}$ terceiro conjunto de idéias se refere à natureza/ meio ambiente como a um sistema autônomo (que se enquadram na categoria $\mathrm{N}$, de idéias que definem nature$\mathrm{za} /$ meio ambiente como uma estrutura com leis dinâmicas próprias). Essa última é uma categoria pouco melhor definida que a categoria $\mathrm{M}$, também está circunscrita a um campo lexical amplo, mas com a peculiaridade de ser mais complexo (por exemplo, há referências a florestas ao mesmo tempo que ao entorno urbano na construção do sentido da dimensão natureza/meio ambiente).

Note-se que 114 participantes, dentre os 355 respondentes (32\%), não produziram nenhuma idéia que pudesse expressar, minimamente, a dimensão natureza/meio ambiente. Esta hesitação em tentar responder com uma definição de desenvolvimento sustentável também deve ser interpretada como índice do conhecimento dos respondentes acerca dos temas relativos ao meio ambiente. Esses são resultados coerentes com aqueles encontrados no relato de Crespo (2001), em que se vê que a maior parte dos brasileiros só consegue representar a idéia de meio ambiente como consistindo em fauna e flora.

$\mathrm{O}$ segundo conjunto de resultados se refere às opções sintáticas e semânticas realizadas pelos respondentes - ou seja, o lugar que ocupa cada uma das expressões que se refere a uma das dimensões na oração -, os verbos e os qualificativos que se referiam especificamente à relação entre desenvolvimento e natureza/meio ambiente. A Tabela 4 mostra que é alto o número de pessoas que não produziu respostas que contivessem as duas dimensões para representar a relação mútua entre desenvolvimento e natureza/meio ambiente (132 participantes, quase $40 \%$ do total). A maioria dos participantes que representa a relação entre desenvolvimento e natureza o faz atribuindo maior importância ao primeiro. Em seguida, a representação da não-relação entre essas duas dimensões; a representação de equilíbrio nesta relação; e a representação que prioriza a natureza.

Tabela 4 Freqüiencia das Categorias da Relação Desenvolvimento-Natureza

\begin{tabular}{lll} 
Categorias & Frequiência & $\%$ \\
& & \\
\hline Nenhuma & 132 & 37,2 \\
$\mathrm{D}>\mathrm{N}$ & 117 & 33,0 \\
$\mathrm{D} “ \mathrm{~N}$ & 62 & 17,4 \\
$\mathrm{D}=\mathrm{N}$ & 25 & 7,0 \\
$\mathrm{D}<\mathrm{N}$ & 19 & 5,4 \\
& & \\
\hline Total & 355 & 100,0
\end{tabular}


Psicologia \& Sociedade; 20 (1): 134-143, 2008

Segundo o estudo de Crespo (2001), em que ela relatou a opinião dos brasileiros sobre o que deve ter prioridade, a preservação do meio ambiente é o que aparece como prioridade (p. 17). No entanto, esse estudo também apontava um crescimento do número de pessoas que acreditava na prioridade para o desenvolvimento econômico em relação a um estudo realizado anteriormente por ela mesma. Os resultados acima apresentados parecem mostrar a realização daquilo que era uma tendência, já que à maior parte das respostas foi atribuído mais importância ao desenvolvimento. Outra informação importante é que esse mesmo estudo de Crespo também apontava a crença dos brasileiros em que o desenvolvimento econômico, tal como se realizava no Brasil, não se correlaciona a qualquer dano causado à natureza (p. 18). Essa idéia encontra ressonância na categoria, neste trabalho, que apresenta uma idéia semelhante ( $\left.D^{\prime \prime \prime N}\right)$, sendo aquela que obteve o segundo maior número de ocorrências, isto é, a idéia amplamente difundida entre os universitários respondentes de que não há relação necessária entre o desenvolvimento econômico e os problemas ambientais, desde que se trate do desenvolvimento sustentável.

O terceiro conjunto de resultados foi gerado pelo cruzamento entre a primeira categorização (concepção de natureza) e a segunda (relação desenvolvimento-natureza), dando origem aos dados constantes da Tabela 5.

Algumas características das respostas apresentadas dão notícia da complexidade e multiplicidade das representações da relação entre desenvolvimento e nature$\mathrm{za} /$ meio ambiente: todos os respondentes que deram uma resposta válida à questão $(n=218)$ apresentaram essa relação como potencialmente assimétrica, isto é, o desenvolvimento é sempre potencialmente danoso à natureza/meio ambiente, e o desenvolvimento sustentável é sempre apresentado como uma alternativa a isso. Ora, isso é um índice bastante eloqüente da aprovação dos respondentes com respeito à idéia que fazem de desenvolvimento sustentável. Mesmo que pensemos em explicar isso pela desejabilidade social vinculada à aprovação do desenvolvimento sustentável, isso só torna mais forte a argumentação em favor de que esta é uma idéia de ampla penetração no discurso social.

Com relação ao modo como as ocorrências se distribuem na Tabela 5, o que parece mais relevante é a maior freqüência de três conjuntos de dados entre as 12 possibilidades, as quais chamamos "matrizes de representação discursiva", tendo em conta a importância de suas características discursivas para o discernimento do modo como os respondentes pensam a relação entre $\mathrm{D}$ e $\mathrm{N}$ : D>N e Meio Ambiente (51/218, ou 23\%); D>N e Recursos Naturais (57/215, ou 26\%), e D "N e Meio Ambiente $(47 / 215$, ou $22 \%)$.
Tabela 5

Resultado do cruzamento entre categorias da relação desenvolvimento-natureza (D $x N)$ e Concepções de Natureza

\begin{tabular}{ccccc}
\hline $\begin{array}{c}\text { Relação D x } \\
\mathrm{N}\end{array}$ & $\begin{array}{c}\mathrm{M} \\
\text { (meio } \\
\text { ambiente) }\end{array}$ & $\begin{array}{c}\mathrm{N} \\
\text { (natureza) }\end{array}$ & $\begin{array}{c}\mathrm{R} \\
\text { (recursos } \\
\text { naturais) }\end{array}$ & Total \\
\hline $\mathrm{D}=\mathrm{N}$ & 14 & 4 & 7 & 25 \\
$D>N$ & 51 & 6 & 57 & 114 \\
$\mathrm{D}<\mathrm{N}$ & 5 & 6 & 6 & 17 \\
$D ? N$ & 47 & 1 & 14 & 62 \\
\hline Total & 117 & 17 & 84 & 218 \\
\hline
\end{tabular}

Denominamos esses três conjuntos de dados de matrizes de representação não apenas por causa de sua maior frequiência em relação aos outros, mas também por causa de certa coerência e sentido que podem ser atribuídos a eles. As pessoas que pensam a dimensão natureza como Recursos Naturais (R) representam a relação entre desenvolvimento e natureza com um modo de se expressar em que a necessidade de desenvolvimento vem primeiro e se faz uma concessão às necessidades de preservação da natureza, ou seja, desenvolvimento prepondera sobre natureza. As pessoas que pensam a dimensão natureza como Meio Ambiente (M) se dividem entre aquelas que dão mais importância a desenvolvimento numa relação em que as dimensões desenvolvimento e natureza/meio ambiente estão em tensão $(D>N)$, e aquelas que têm em mente a não-relação entre desenvolvimento e natureza/meio ambiente ( $\left.\mathrm{D}^{\text {“" }} \mathrm{N}\right)$. Tendo em conta nosso objetivo de investigar a relação entre desenvolvimento e natureza/meio ambiente a partir da concepção de natureza, podemos pensar que esses resultados nos sugerem que uma concepção de natureza mais "acabada" ( $\mathrm{R}$ ou $\mathrm{N}$ ) é mais compatível com uma forma de reconhecimento da relação mutuamente implicativa de $\mathrm{D}$ e $\mathrm{N}$ (principalmente: $\mathrm{D}>\mathrm{N}$ ); o outro lado dessa equação é a compatibilidade entre $\mathrm{M}$ (categoria pouco definida para expressar natureza) e $\mathrm{D}$ “" $\mathrm{N}$ (o não reconhecimento da relação mutuamente implicativa de D eN). E, não obstante, as frequiências sugerem um certo "trânsito" entre essas representações, o que seria a ocorrência de $M \& D>N$.

Pela observação das características semânticas de cada uma das matrizes de representação, extraímos o seguinte exemplo de definição que apresenta a primeira das matrizes: 
É um desenvolvimento que consome o ambiente (recurso) de forma que esse ambiente consegue se restabelecer, tornando possível a continuidade do desenvolvimento. Por exemplo, se uma empresa corta árvores, deve ser possível que mais árvores cresçam para compensar, caso contrário as árvores acabariam e o desenvolvimento, conseqüentemente, também.

Nessa definição, a dimensão N comparece como "ambiente (recurso)", e quando é qualificada com um exemplo, ela é "árvores", árvore-recurso, e como tal, pode "acabar". O tipo de relação entre D e N, se estabelece, primeiramente, como uma relação de "consumo", mas um tipo de consumo específico, um que permita, que conceda ao ambiente consumido que se "restabeleça". Ora, o restabelecimento do ambiente-recurso tem seu sentido em "tornar possível a continuidade do desenvolvimento", e assim, o desenvolvimento está no começo e no fim, e o lugar reservado ao ambiente recurso é o de meio. Esse tipo de relação semântica é que se torna índice para que o tipo de relação entre D e N seja categorizada como assimétrica e com maior importância para $\mathrm{D}$, numa relação entre $\mathrm{D}$ e o ambiente-recurso $(\mathrm{R})$.

Essa matriz de representação $(R \& D>N)$ sugere a reprodução de um discurso "economicista", que leva em conta a natureza como um bem a ser utilizado pelo homem, segundo as suas necessidades e capacidade de uso e aproveitamento, servindo aos objetivos de desenvolvimento, no entanto, uso e aproveitamento limitados pela disponibilidade dos bens naturais. Por isso, ainda que reconheça sua importância (da natureza/meio ambiente), isso se articula à idéia de que a escassez de recursos naturais põe em risco as condições de desenvolvimento. Como é composta pela idéia de que garantir o desenvolvimento deve ser o objetivo do desenvolvimento sustentável, o que está na base da preocupação ambiental que esse tipo de representação agrega é, essencialmente, uma ambientalismo de base antropocêntrica; e, porque o que dá sentido a essa preocupação é o perigo de escassez dos recursos naturais, desconsidera as características estruturais e sensíveis de natureza/meio ambiente, pela suposição implícita de que “em não se retirando muito, não haverá impacto". Exclui, também, a idéia de que o homem faz parte de naturezal meio ambiente. Essa representação é economicista porque o contexto de produção de sentido para a dimensão natureza/meio ambiente é o discurso econômico, as mobilizações de sentido referentes a essa dimensão são matizadas pelas categorias desse discurso: como "recursos naturais", o valor que se agrega à natureza/meio ambiente é vinculado à idéia de produção de riquezas e, desse modo, sua representação também; o modo como é apresentada a relação entre desenvolvimento e natureza/meio ambiente é o "uso racional", pelo homem, dos recursos naturais, o que implica o cuidado com o ambiente como uma concessão. Em comparação a outras ocorrências, essa é uma repre- sentação organizada e coerente, e talvez isso indique sua pertença, como repertório interpretativo das relações entre desenvolvimento e natureza/meio ambiente, ao discurso social.

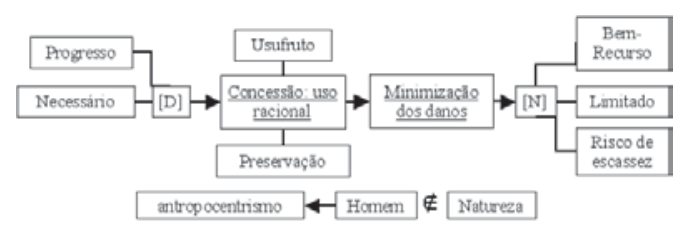

Figura 3. Discurso "economicista".

Na minha concepção Desenvolvimento Sustentável é uma forma de conduzir o progresso, utilizando os recursos tecnológicos sempre em favor do bem-estar das pessoas, porém tendo sempre uma preocupação com o meio ambiente para não deixar que a natureza seja prejudicada e, futuramente, os seres humanos venha a sofrer com isso.

Aqui a dimensão Né apresentada sem qualificadores que especifiquem o seu significado, a não ser aqueles que apontem para a sua fragilidade e o perigo que decorre do "progresso" como acontecimento. Quanto à relação entre os esforços para a consecução do progresso e o "meio ambiente", se afirma o "favor" ao "bem-estar das pessoas", e em seguida se tem uma oração subordinada que, embora operada por uma conjunção adversativa, tem valor concessivo, para dizer de uma "preocupaçãosempre", que não chega a ser combativa, mas apaziguadora, e uma intenção protetora cuja demanda é constante. A concessão é o sentido mais fundamental para a relação entre $\mathrm{D}$ e $\mathrm{N}$.

A segunda matriz de representação $(M \& D>N)$ sugere a reprodução de um discurso "bem intencionado". Essa intenção, que se faz discernível nas respostas que fazem parte desse grupo, não traz consigo outros elementos que a qualifiquem. O desenvolvimento é apresentado como necessário, embora afete de algum modo à natureza/meio ambiente. Esta é apresentada como frágil e em perigo, e, no entanto, não são discerníveis suas características, aquelas que contribuem para a sua fragilidade, tampouco as características situacionais que determinam o perigo que é aludido para dizer sobre a natureza/meio ambiente. Ora, a exigüidade de significado para a dimensão natureza/meio ambiente empobrece as possibilidades de sentido acerca da relação entre as duas dimensões, a qual, com respeito a essa matriz discursiva, também se apresenta como uma concessão e uma demanda constante de proteção para natureza por ser contado sempre o risco a ela, e mais nada inteligível, além disso. Essa se torna uma preocupação, de certo modo, "irrefletida", sem motivos claros, por carecer de recursos semânticos para a apreciação da relação entre desen- 
volvimento e natureza/meio ambiente. Não obstante, essa representação ainda assim dispõe como em conflito as duas dimensões D e N. As necessidades de desenvolvimento, seja econômico, social, etc., constituem uma idéia recuperada de um discurso social que, por ser mais difundida, mais debatida, tanto na mídia quanto em outros espaços de interação social, dispõe de apelo mais sólido e melhor estabelecido, não só no discurso mas também no imaginário social. Dessa forma, essas necessidades assumem prioridade relativa à idéia concorrente que é a preocupação com a natureza/meio ambiente.

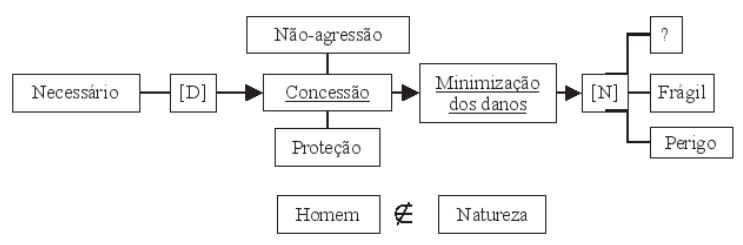

Figura 4. Discurso "bem intencionado".

Entendo por Desenvolvimento Sustentável o desenvolvimento de uma sociedade em todos os seus aspectos integrando este com a natureza sem agredi-la nem interferir em seu funcionamento.

Novamente, a dimensão N é não-apresentada e aludida, porque lhe faltam todos os tipos de qualificadores; é referida como coisa. Muito embora se possa pensar que tudo o que é a natureza não precise ser dito por ser bem conhecido, o modo como a palavra "natureza" serve à construção da definição de desenvolvimento sustentável é que lhe torna uma coisa-palavra, que as outras palavras tangem para lá e para cá: "integrando este com a natureza", "sem agredi-la", "nem interferir no seu funcionamento". Assim, o que dessa idéia de natureza se mostra é que funciona, sofre ameaça de agressão e que tem no desenvolvimento o seu outro do qual está disjunta até o advento de desenvolvimento sustentável. Justamente no quis diz respeito à relação entre $\mathrm{D}$ e $\mathrm{N}$, é de uma não interferência que se trata, uma não agressão, um não-toque, a não-relação, e assim, mesmo o "integrar" começa a se parecer com uma harmoniosa convivência de vizinhos.

A terceira matriz de representação $(M \& D$ “ "N) sugere um discurso "esvaziado", pois apresenta a natureza de modo inespecífico e não dispõe de recursos para refletir a relação entre as duas dimensões. A dimensão nature$\mathrm{za} /$ meio ambiente, objeto indefinido, pode ser poupada pelo tipo de desenvolvimento que é o desenvolvimento sustentável, um tipo que não lhe afeta. Essa é a representação da possibilidade de não-relação entre desenvolvimento e natureza/meio ambiente: o desenvolvimento ainda é apresentado como sendo necessário, a natureza/meio ambiente como frágil, e sua relação é de não-implicação, ou seja uma nãorelação. Desse modo, além de desconsiderar algumas das características fundamentais de natureza/meio ambiente (seus aspectos sistêmicos, dinâmicos, etc.), e de excluir o homem como parte disso, supõe um desenvolvimento que não lhe afeta.

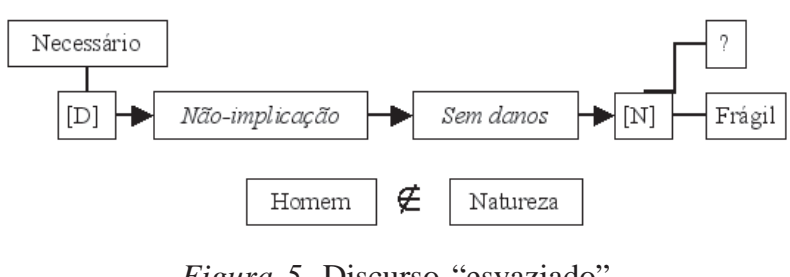

Se observarmos em sequiência as três representações gráficas das três matrizes de representação discursiva, duas impressões podem nos ocorrer: o parentesco entre as três representações - pois compartilham diversos elementos - e o seu empobrecimento gradual (ver Figuras 3, 4 e 5). Isso pode sugerir uma espécie de progressão, em que o discurso economicista corresponde à representação daqueles que mais "conhecem" acerca dos problemas ambientais e também de sua solução (ou, pelo menos, de uma possibilidade de solução), enquanto o discurso esvaziado corresponde à outra ponta do fenômeno, aqueles que "desconhecem". Mas uma outra leitura para os dados também pode estar sugerida, que é a presença de dois discursos, um de velamento - aquele que chamamos de esvaziado - da relação (danosa para a natureza) entre desenvolvimento e natureza, isto é, a não-relação, e outro de apaziguamento, ou uma fala em favor do que é possível - aquele que chamamos de economicista - que apresenta a relação entre desenvolvimento e natureza como uma relação de danos, mas que podem ser minimizados.

Em todo caso, essas não são as únicas formas em que se pode pensar a relação entre desenvolvimento e natureza. As respostas aqui apresentadas revelam também naquilo que elas ignoram: formas de se pensar a relação entre natureza e desenvolvimento em que a natureza seja um valor em si mesma, tornando a natureza, o seu cuidado, tão importante ou mais importante do que as necessidades de progresso e desenvolvimento.

\section{Considerações Finais}

De um modo mais geral, o conjunto dos resultados apresentados dá consistência às observações feitas sobre o pouco conhecimento das pessoas acerca do que é desenvolvimento sustentável, apontando, mais uma vez, para a ausência de vários elementos que compõem essa idéia (Nunes, 1999; Pinheiro et al., 2005). No entanto, esse estudo tem a virtude de apontar para a complexidade das representações da relação entre o homem e a natureza. 
Indo além de sugerir um pouco conhecimento dos respondentes dessa pesquisa acerca do tema desenvolvimento sustentável - o que já teria importante repercussão sobre os estudos do comportamento pró-ecológico -, uma visada ao discurso que suas respostas veiculam tornou possível o acesso aos repertórios interpretativos que mediam o pensamento dessas pessoas no que diz respeito a como devem ser empreendidos os esforços em busca de desenvolvimento, e isto em função de uma concepção daquilo que seja a natureza/meio ambiente.

Isso nos leva, certamente, a reconsiderar a importância dos significados atribuídos à natureza no entendimento do modo como as pessoas aderem a uma ou outra opinião sobre o desenvolvimento. O significado atribuído à natureza aparece então como um possível indicador de conhecimento e comportamento pró-ambiental, o que justifica que seja contado como tema de um programa de estudos sobre conduta sustentável. Retomando as hipóteses iniciais, de que o conhecimento afeta o comportamento e de que a concepção de natureza implica uma forma de pensar as possibilidades de relação entre ela e o desenvolvimento, são possíveis, pelo menos, duas considerações: (a) as três matrizes discursivas que comparecem nas respostas estudadas se apresentam como três formas distintas, ou três possibilidades, de justificar um certo desapreço pelas relações humano-ambientais e, desse modo, desinteresse por certos tipos de comportamento pró-ambiental; (b) o modo como se pensa a natureza é um elemento estrutural da forma de se pensar a relação entre homem e natureza.

Assim, é possível pensar que a produção do que se chama de consciência ambiental, ou dos problemas ambientais e da necessidade de solução, tem uma relação muito íntima com a produção de sentidos sobre a natureza. Ora, se essa opinião importa no que concerne aos esforços de produção da consciência dos problemas ambientais que enfrentamos e das soluções de que realmente dispomos, a influência da concepção de natureza que temos importa a campos como a educação científica e ambiental, inclusive pelo papel que têm na construção dessa concepção e no manejo dessa idéia, como parte da eficácia de sua ação em favor dos interesses pró-ecológicos.

Os resultados para os quais aponta este estudo são possíveis pela dispersão das idéias relacionadas à natureza, para o que contribui o discurso social em todas as suas fontes, entre elas o discurso político e científico, e que um quadro menos disperso de sentidos acerca de natureza poderia contribuir positivamente para a construção de discurso mais "sustentável". Se, por um lado, esse estudo sugere com que idéias sobre desenvolvimento a concepção de natureza ( $\mathrm{R}$ - conjunto de recursos naturais) é mais compatível; por outro, sugere que a con- cepção de natureza como algo com características sistêmicas, com um valor intrínseco, de que faz parte também o homem, e sensível à sua interferência, ainda se mantém pouco explorada para mediar outras relações e outras idéias sobre a relação entre o homem e a natureza. Por isso mesmo, por causa das idéias contidas entre os resultados e a falta de outras podem fazer pensar sobre qual o compromisso a que esses discursos atendem: um compromisso construído por toda uma sociedade com a inércia relativa ao enfrentamento dos problemas ambientais, a qual favorece os interesses econômicos mais imediatos em detrimento de outros tipos de práticas e discursos que poderiam sustentar um compromisso com o futuro dessa mesma sociedade.

\section{Notas}

1. Versão preliminar deste trabalho foi apresentada no IV Congresso Norte-Nordeste de Psicologia (maio/2005, Salvador/BA), sob o título Exploração das definições de desenvolvimento sustentável de estudantes universitários e análise da relação entre seus temas, variáveis sócio-demográficas e compromisso pró-ecológico.

2. Os autores agradecem: ao CNPq, pelo apoio financeiro a projeto de pesquisa e bolsa de produtividade em pesquisa para o segundo autor e pela bolsa de iniciação científica ao primeiro autor; aos alunos, professores e dirigentes dos cursos envolvidos, pela participação; a Ana Beatriz B. Cortez, Fernanda F. Gurgel, Mônica O. Link e Thiago F. Pinheiro, por variadas formas de contribuição ao projeto de pesquisa do qual este relato é parte.

\section{Referências}

Aragonés, J. I., Izurieta, C., \& Raposo, G. (2003). Revisando el concepto de desarrollo sostenible en el discurso social. Psicothema, 15(2), 221-226.

Aragonés, J. I., Raposo, G., \& Izurieta, C. (2000). Las dimensiones del desarrollo sostenible en el discurso social. Estudios de Psicología, 22(1), 23-36.

Barbieri, J. C. (1997). Desenvolvimento e meio ambiente. Petrópolis, RJ: Vozes.

Bardin, L. (1979). Análise de conteúdo. Lisboa, Portugal: Edições 70.

Bauer, M. W. (2002). Análise de conteúdo clássica: Uma revisão. In M. W. Bauer \& G. Gaskell (Eds.), Pesquisa qualitativa com texto, imagem e som: Um manual prático (pp. 189-217). Petrópolis, RJ: Vozes.

Bonnes, M., \& Bonaiuto, M. (2002). Environmental Psychology: From spatial-physical environment to sustainable development. In R. B. Bechtel \& A. Churchman (Eds.), Handbook of Environmental Psychology (2. ed., pp. 28-54). Nova York: Wiley.

Comissão Mundial sobre Meio Ambiente e Desenvolvimento. (1988). Nosso futuro comum. Rio de Janeiro, RJ: Editora da Fundação Getúlio Vargas.

Corral, V. (2001). Comportamiento proambiental: una introducción al estudio de las conductas protectoras del ambiente. Santa Cruz de Tenerife, España: Resma. 
Crespo, S. (2001). O que o brasileiro pensa do meio ambiente e do consumo sustentável. Retirado em 22 out. 2005, de http:// www.iser.org.br/portug/meio_ambiente_brasil.pdf

Drummond, J. A. (1999). Desenvolvimento sustentável: Debates em torno de um conceito problemático. História, Ciências, Saúde-Manguinhos, 5(3), 755-761.

Frey, K. (2001). A dimensão político-democrática nas teorias de desenvolvimento sustentável e suas implicações para a gestão local. Ambiente \& Sociedade, 9(1), 115-148.

Frick, J., Kaiser, F. G., \& Wilson, M. (2004). Environmental knowledge and conservation behavior: Exploring prevalence and structure in a representative sample. Personality and Individual Differences, 37(8), 1597-1613.

Kollmuss, A., \& Agyeman, J. (2002). Mind the gap: Why do people act environmentally and what are the barriers to proenvironmental behavior? Environmental Education Research, 8(3), 239-260.

McKenzie-Mohr, D., \& Oskamp, S. (1995). Psychology and sustainability: An introduction. Journal of Social Issues, 51, 114.

Minayo, M. C. S. (1992). O desafio do conhecimento: Pesquisa qualitativa em saúde. São Paulo, SP: Hucitec.

Nunes, F. L. (1999). A noção de desenvolvimento sustentável em estudantes brasileiros. Relatório de pesquisa não-publicado, Conselho Nacional de Desenvolvimento Científico e Tecnológico, Brasília, DF.

Oskamp, S. (2000). A sustainable future for humanity? How can psychology help? American Psychologist, 55(5), 496-508.

Pinheiro, J. Q. (2003). Psicologia Ambiental brasileira no início do século XXI. Sustentável? In O. H. Yamamoto \& V. V. Gouveia (Eds.), Construindo a psicologia brasileira: Desafios da ciência e da prática psicológica (pp. 279-313). São Paulo, SP: Casa do Psicólogo.

Pinheiro, J. Q. (2005). Perspectiva temporal e conduta sustentável. Relatório de pesquisa não-publicado, Conselho Nacional de Desenvolvimento Científico e Tecnológico/CNPq, Universidade Federal do Rio Grande do Norte, Natal, RN.

Pinheiro, J. Q., Maux, A. A. B., \& Nunes, F. L. (2000). Environmental concern, anthropocentrism and sustainability: The relevance of a time perspective. Comunicação apresentada na 16a Conferencia de International Association of PeopleEnvironment Studies/IAPS, Paris.

Pinheiro, J. Q., Matias, H. J. D., Cortez, A. B. B., Pinheiro, T. F., Gurgel, F. F., \& Link, M. O. (2005). Exploração das definições de desenvolvimento sustentável de estudantes universitários e análise da relação entre seus temas, variáveis sócio-demográficas e compromisso pró-ecológico [Resumo]. In Comissão Organizadora (Ed.), Anais do IV Congresso Norte-Nordeste de Psicologia. Salvador, BA: Conselho Regional de Psicologia CRP-03 (Bahia e Sergipe).

Pol, E. (2001). Ejes de tensión y nueva agenda para la Psicología Ambiental. Uma perspectiva Europea. In E. Tassara (Ed.), $P a-$ noramas interdisciplinares para uma psicologia ambiental do urbano (pp. 51-67). São Paulo, SP: FAPESP.

Pol, E. (2002). The theoretical background of the City-IdentitySustainability Network. Environment and Behavior, 34(1), 825.

Schmuck, P., \& Schultz, W. P. (2002). Psychology of sustainable development. Dordrecht, Holanda: Kluwer.

Schmuck, P., \& Vlek, C. (2003). Psychologists can do much to support sustainable development. European Psychologist, 8(2), 66-76.
Scott, W. (2002). Minds, gaps, models, and behaviours. Environmental Education Research, 8(3), 237-238.

Souza, E. A., Filho. (1995). Análise de representações sociais. In M. J. P. Spink (Ed.), O conhecimento no cotidiano: As representações sociais na perspectiva da psicologia social (pp. 109145). São Paulo, SP: Brasiliense.

Thompson, S. C. G., \& Barton, M. A. (1994). Ecocentric and anthropocentric attitudes toward the environment. Journal of Environmental Psychology, 14, 149-157.

Hugo Juliano Duarte Matias é Mestrando em

Psicologia pelo Programa de Pós-Graduação em Psicologia da Universidade Federal do Rio Grande do Norte (UFRN). Endereço para correspondência: Rua das Hortências, 375a, Capim Macio, Natal, RN, 59.078-140. hugojdm@yahoo.com.br

José de Queiroz Pinheiro é Doutor em Psicologia Ambiental pela Universidade do Arizona (Tucson, EUA), é Professor Adjunto na UFRN e Coordenador do Grupo de Estudos Inter-Ações Pessoa-Ambiente. pinheiro@cchla.ufrn.br

Desenvolvimento Sustentável: Um Discurso sobre a Relação entre Desenvolvimento e Natureza

Hugo Juliano Duarte Matias e José de Queiroz Pinheiro

Recebido: 20/03/2007

$1^{\mathrm{a}}$ revisão: $16 / 07 / 2007$

Aceite final: 18/10/2007 